\title{
O Estatuto da Pitié nas Obras de Rousseau
} THE STATUS OF PITIÉ IN THE WORKS OF ROUSSEAU

\author{
Marisa Alves Vento ${ }^{1}$
}

\begin{abstract}
RESUMO: A hipótese apresentada neste texto é a de que a piedade, que Rousseau também denomina "segundo princípio", encontrado por ele "ao meditar nas primeiras e mais simples operaçóes da alma humana”, não é um princípio antagônico ao amor de si. Pretende-se mostrar como o dualismo radical dos princípios se renderia diante da evidência de uma unidade representada por um duplo movimento: o de fixar-se ou aderir-se em si (amor de si) e o de expansão, que seria a expressão da piedade. Desse ponto de vista, o segundo princípio teria um status complementar do amor de si e náo opositivo a ele, como algumas interpretaçôes propõem. Entretanto, é uma discussão complexa, uma vez que nela estão implicadas as controvérsias entre os intérpretes de Rousseau em relação à possível divergência da noção de piedade, no Segundo Discurso, no Emílio e no Ensaio sobre a Origem das Línguas, além das discussôes em torno da datação do Ensaio.
\end{abstract}

PALAVRAS-CHAVE: Rousseau. Amor de si. Piedade.

Victor Goldschmidt, um dos grandes comentadores de Rousseau, observou que a originalidade de Rousseau consistiu em dar aos princípios do amor de si e piedade um novo sentido. A fim de se investigar qual seria esse novo sentido, é necessário seguir a linha de raciocínio das interpretaçóes que criticam o reducionismo do princípio do amor de si ao puro instinto de conservação. O recurso ao "apelo da natureza", bem pouco original inclusive, já estava expresso, como cita Goldschmidt, numa frase de Diderot: "[...] faça de modo que todas as tuas açóes tendam à conservação de ti mesmo, e à conservação dos outros, é o apelo da natureza" (GOLDSCHMIDT, 1974, p. 333). A frase pode ainda, frisa o comentador, ser assimilada e reduzida à vontade, seja aos ensinamentos de Pufendorf, seja à doutrina estoica ou, até mesmo, ao "sumário da lei evangélica". Deve-se, pois, concordar com Goldschmidt, ao observar que as arbitrariedades simplificadoras apagam todas as distinçóes específicas ao preço de uma ideia geral e vaga, revelando, assim, o desconhecimento "[...] não somente do papel do método no estabelecimento

${ }^{1}$ Doutora em Filosofia pela UNICAMP. Professora de Ética e Filosofia do Instituto Federal de Educação, Ciência e Tecnologia de Goiás. E-mail: ventomarisa@gmail.com

http://dx.doi.org/10.1590/S0101-317320150004000013 
de um dogma filosófico, mas a existência mesma desse método que na filosofia de Rousseau é primordial" (GOLDSCHMIDT, 1974, p. 334). Sendo assim, é preciso reconhecer que a interpretação dos princípios estabelecidos por Rousseau não pode se restringir a limites estreitos. Tampouco é cabível julgar que a sua concepção sobre essa matéria se assemelha às concepçôes dos pensadores que haviam considerado e elaborado teorias partindo desse mesmo ponto, ou seja, do instinto de conservação. De outro modo, não haveria um sentido novo, como Goldschmidt aponta.

No prefácio ao Segundo Discurso, antes de abordar os dois princípios percebidos na gênese da individualidade humana, Rousseau explica que deixará "[...] de lado todos os livros científicos que apenas ensinam a ver os homens como eles se fizeram”. É possível notar que ele pretende ir além das formulaçóes do seu tempo e colocar, como observa Baczko, "[...] tudo em suspensão para fundar a subjetividade da alma a partir da autoafeição própria à vida" (BACZKO, 1974, p. 213). Rousseau não levará em conta os atos do pensamento e nem os da percepção sensível, característicos das elaboraçóes sensualistas, mas a vida em seu sentimento de si, partindo da premissa de que tudo o que é imediatamente dado é o sentimento do Eu. Todavia, se na Profissão de fé, é possível notar uma hesitação, quando responde à questão que se coloca: "[...] tenho um sentimento próprio de minha existência ou só a sinto através das minhas sensaçóes?” Há uma evidência incontornável no pensamento do filósofo: “[...] minhas sensaçôes estâo em mim porque elas me fazem sentir a minha existência” (ROUSSEAU, 1969, p. 570. Isto é, o sentimento de existência é irredutível às sensaçôes, é a experiência autoafetiva que o revela pré-reflexivamente: “[...] o primeiro sentimento do homem foi o de sua existência, o primeiro cuidado o de sua conservaçáa”, pode-se ler no Segundo Discurso. No tocante a essa questão, apesar de ainda não ter sido estabelecida com precisão a relação entre o sentimento de existência e a autoafeição primordial ou amor de si, um fragmento de Rousseau, citado por Bronislaw Baczko, indica claramente essa relação:

O estado natural de um ser passível e mortal como o homem é o de comprazer-se no sentimento de sua existência, de sentir com prazer o que tende a conservá-lo e com sofrimento o que tende a destruí-lo, é nesse estado natural e simples que é preciso buscar a fonte de nossas paixóes. [...] Qual é entáo esse princípio, eu já o disse: o desejo de existir. Tudo o que pareça estender ou reforçar nossa existência nos agrada, tudo que pareça destruí-la nos aflige. Tal é a fonte primitiva de nossas paixóes. (ROUSSEAU, 1961, p. 1324-1325). 
É notável perceber que Rousseau já havia pensado a autoafeição como uma estrutura universal da experiência do vivente. E, indo um pouco além das interpretaçóes correntes, pode-se sustentar que a redescoberta rousseauniana do amor de si, confundindo-se com a própria vida, antecipa o que se encontra na base da tese fenomenológica radical de Michel Henry, filósofo que, ao investigar a essência do fenômeno vida, postula um "[...] sofrer primordial situado no cerne da experiência radicalmente imanente que o indivíduo vivo faz de cada uma de suas vivências" (GELLY, 2009, p. 1). A esse sofrer ou pathos primordial ou autoafeição, Michel Henry designa o plano de imanência em que a vida se experimenta a si mesma, abaixo de toda transcendência intramundana, de toda intencionalidade, ou seja, é a carne, o corpo apreendido do ponto de vista da estrita subjetividade ${ }^{2}$.

Retornando à investigação proposta anteriormente sobre o novo sentido dado por Rousseau, façamos entrar em cena uma questão levantada por Luc Vincenti em relação à busca pelo bem-estar, na qual o indivíduo movido por seu amor de si se lança. Segundo esse autor, que interpreta Rousseau à luz de Malebranche, na esfera humana ocorre o que denomina superação do "ser pelo bem-estar”, operada numa dimensão espiritual (VINCENTI, 2001, p. 45). O intérprete mostra que, nessa busca pelo bem-estar, processa-se no indivíduo humano uma superaçáo da sensibilidade pela espiritualidade, observando-se a continuidade ou, melhor dizendo, a permanência do amor de si, o qual, conforme se vê reiteradas vezes nos escritos de Rousseau, é essencial a todo ser capaz de sentir-se a si mesmo (ROUSSEAU, 1969, p. 588) e nunca abandona o homem, enquanto ele vive.

Deve-se notar, entretanto, que existem distinçóes dos domínios desse bem-estar: "O amor de si não é uma paixão simples; mas ela possui dois princípios, a saber, o ser inteligente e o ser sensível, cujo bem-estar não é o mesmo" (ROUSSEAU, 1969, p. 936). É coerente concordar com Luc Vincenti que, embora haja nesse aspecto uma distinção, existe em ambos os domínios a identidade da busca. Assim, os domínios podem ser pensados em conjunto, a partir da hierarquizaçáo dos diferentes momentos dessa busca pelo bem-estar. De fato, sublinhando a ambiguidade desse bem-estar que é, ao mesmo tempo, sensível e espiritual, o próprio Rousseau nos conduz a essa

\footnotetext{
${ }^{2}$ É importante notar que a concepção sobre a corporeidade desenvolvida por Henry a diferencia das teorias contemporâneas, cujas concepçóes partem da filosofia e biologia do século XIX, impregnadas de pressupostos mecanicistas.
} 
conclusão. Ao explicitar a significação, não menos ambígua atribuída ao termo sensibilidade, ele assinala:

A sensibilidade é o princípio de qualquer ação [...], há uma sensibilidade física e orgânica que, puramente passiva, parece ter como fim apenas a preservaçáo de nosso corpo e de nossa espécie, pelo direcionamento do prazer e da dor. Há uma outra, que eu chamo de sensibilidade ativa e moral, que é nada mais é do que ligar nossos afetos aos seres que nos são estranhos. (ROUSSEAU, 1959, p. 805).

Vê-se que dois aspectos da sensibilidade ativa e moral são distinguidos, nesse caso, um positivo e um negativo, e, no que tange à "ação positiva e atrativa", um movimento "simples da natureza", Rousseau faz uma vinculação imediata: "A sensibilidade ativa deriva imediatamente do amor de si" (ROUSSEAU, 1959, p. 805). Em seguida, ele complementa, afirmando que “[...] é muito natural que aquele que se ama busque estender ou reforçar o sentimento do seu ser" (ROUSSEAU, 1959, p. 805). Ora, essa sensibilidade positiva e atrativa que Rousseau deriva do amor de si constitui ao mesmo tempo duas propriedades, a de aderir-se a si (reforçando o sentimento do nosso ser) e a de estender-se (expansão espontânea que projeta o ser para fora de si). É essa segunda propriedade que traduz a ideia de um sentimento natural ou, talvez melhor dizendo, de uma potencial "impulsão moral” que liga um indivíduo a outro, cujo exemplo decisivo é a piedade ${ }^{3}$.

Por outro lado, a sensibilidade ativa negativa guarda relação com a transformação sofrida pelo amor de si devido ao "progresso" das relaçóes sociais, que o fizeram degenerar em amor próprio, conforme se verá mais adiante. No Segundo Discurso, a piedade é o segundo princípio, definido como o sentimento natural capaz de moderar, em cada indivíduo, a atividade do amor a si mesmo, garantindo, assim, a conservação mútua de toda a espécie.

Considerando a primazia do primeiro princípio, o amor de si, a hipótese apresentada aqui é a de que a piedade não seria propriamente um princípio antagônico ${ }^{4}$ àquele, como sugerem algumas leituras, mas possuiria

\footnotetext{
${ }^{3}$ Ver a contribuição de Roger Masters para o entendimento dessa relação: "A natureza é a fonte da sensibilidade física, passiva (que leva ao desejo de conservação de si e ao elemento puramente físico do desejo sexual) e, igualmente, a fonte da sensibilidade moral ativa (que como a piedade ou o apego de uma mãe ao seu filho, atrai o afeto de um indivíduo para o outro" (MASTERS, 2002, p. 196).

${ }^{4} \mathrm{O}$ estatuto da piedade foi objeto de sérias controvérsias entre os intérpretes rousseaunianos, Robert Derathé, por exemplo, aponta uma divergência interna entre o Emílio e o Segundo Discurso: “[...] no
} 
um status complementar, até mesmo dele derivado. Ou seja, constituindo o "[...] movimento puro da natureza" (ROUSSEAU, 1964, p. 155), amor de si e piedade formariam uma unidade representada, no entanto, por um duplo movimento: o de fixar-se ou aderir-se a si e o de expansão. Essa interpretação anularia a concepção equivocada de que amor de si e piedade configuram dois princípios opostos, um dizendo respeito a si mesmo, portanto, absoluto, e o outro se referindo à consideração de outrem, logo, relativo. Embora a definição seja exatamente esta, o que pretende mostrar é que se trata, como destacado anteriormente, de um duplo movimento que advém de um único princípio fundamental.

Todavia, antes de prosseguir com essa interpretação, é preciso considerar os enfrentamentos filosóficos que Rousseau precisou realizar, no terreno das discussóes morais, a fim de estabelecer os seus princípios.

Em primeiro lugar, havia a necessidade de explicar a bondade original de um ser que, vivendo isolado, independente, desconhecia as relaçóes com seus semelhantes, sendo incapaz, portanto, de sentir amor ou simpatia por outro. Contra o argumento do egoísmo hobbesiano, era preciso postular um princípio da alma que moderasse o ardor do amor de si em algumas circunstâncias nas quais ele pudesse se exacerbar, isto é, que se manifestasse em combinação com a indiferença ao outro e a repugnância instintiva em vê-lo sofrer, mas, ao mesmo tempo, permanecesse apenas como princípio no estado de natureza, caracterizando a bondade original entendida como um estado de ignorância, tanto em relação ao bem quanto ao mal.

Por outro lado, na sua refutação à ideia de sociedade geral, Rousseau pretendia afastar a hipótese de um sentimento natural de benevolência universal ${ }^{5}$ defendida, por exemplo, por Barbeyrac e Burlamaqui, além de contestar o postulado de uma sociabilidade racional, efeito da consciência de uma identidade da natureza humana, conforme estava posto para Pufendorf. Como, para Rousseau, razão e reflexão só se desenvolvem no homem muito tardiamente, a piedade natural precisava ser apresentada como um limite espontâneo ao amor de si, impedindo-o de estender-se para além dos "[...] limites fixados pela natureza” (ROUSSEAU, 1964, p. 604). Ainda no contexto

Emílio, a piedade se torna um sentimento derivado do amor de si, enquanto que o segundo Discurso opóe estes dois princípios um ao outro" (DERATHÉ, 1948, p. 100).

${ }^{5}$ Ver o Manuscrito de Genebra, onde Rousseau começa por contestar vigorosamente a expressão "gênero humano", a qual oferece uma "[...] ideia puramente coletiva que não supōe qualquer união real entre os indivíduos que o constituem” (ROUSSEAU, 1964, p. 283). 
desses enfrentamentos filosóficos constantes do Segundo Discurso, como nota Goldschmidt, dois movimentos podem ser observados na argumentaçáo de Rousseau sobre a piedade, os quais desempenham um papel fundamental na construção do seu pensamento. $\mathrm{O}$ primeiro movimento vai em direção a Mandeville, autor de uma das mais famosas teorias do interesse, de quem Rousseau retém o argumento da naturalidade da piedade, tornando-o um dos importantes interlocutores, no Segundo Discurso, no contexto da discussão com Hobbes.

Rousseau reconhece, naquele a quem acusa de ser o mais implacável detrator das virtudes humanas, a capacidade de ter percebido que, se a piedade não tivesse sido dada pela natureza aos homens, em apoio à razão, estes não passariam de uns monstros. Rousseau mantém a ideia do autor da Fábula das Abelhas, que admite a propensão natural do homem para sentir piedade e, ato contínuo, afirma o que Mandeville nega existir: as virtudes sociais. Nosso autor assume, pois, que a piedade não é em si mesma uma virtude, porém, um princípio que os selvagens possuem em maior nível de perfeiçáo do que os homens polidos e cultivados, do qual decorrem todas as virtudes sociais dos homens.

O segundo movimento tem sob a mira um outro defensor da doutrina do interesse: La Rochefoucauld, cujas máximas declaravam que todas as açóes humanas são dirigidas pelo amor próprio. Quando sentimos piedade, é só aparentemente que o sentimento se dirige para o outro, na verdade, é para nós mesmos que esse sentimento se volta. Sentimos piedade, porque nos colocamos no lugar do outro que sofre e, vendo, por conseguinte, como é sofrer, deliberamos ajudá-lo para contar com alguma ajuda no futuro. Para responder a esse raciocínio e mostrar que a piedade natural não é baseada no interesse calculado, Rousseau dá um toque de complexidade ao argumento e reordena os elementos da análise. O princípio fundamental motivador das açôes humanas, em La Rochefoucauld, é o princípio egoísta do amor próprio, que busca vantagens pessoais. Rejeitando essa hipótese, Rousseau localiza um estágio da vida humana onde o amor próprio não existe, como bem mostra a nota XV ao Segundo Discurso, afirmando que o amor de si é a fonte do agir humano, que ele é absolutamente distinto do amor próprio, forma egoísta e corrompida produzida pelas relaçóes sociais. Entretanto, Rousseau mantém a premissa de La Rochefoucauld de que nos colocamos no lugar daquele que sofre, dando a esse fenômeno o nome de identificação: 
A ser verdadeiro que a comiseração não passa de um sentimento que nos coloca no lugar daquele que sofre, sentimento vivo e obscuro no selvagem, desenvolvido e fraco no homem civil [...]. A comiseração, com efeito, mostrar-se-á tanto mais enérgica quanto mais intimamente se identificar o animal espectador com o animal sofredor. Ora, é evidente que essa identificação deveu ser infinitamente mais íntima no estado de natureza do que no estado de raciocínio. (ROUSSEAU, 1964, p. 156).

A afirmação dessa identificação do sofrer de outrem, ainda no estado de natureza, rendeu bons comentários em torno do pensamento de Rousseau. Embora não seja possível aprofundar a questão, a problemática originada da suposta divergência da noção de piedade, no Segundo Discurso, no Emílio e no Ensaio sobre a Origem das Linguas, é fecunda. Envolve, também, as discussóes em torno da datação do Ensaio, se ele seria anterior ou posterior ao Segundo Discurso. Em um capítulo da Gramatologia, Jacques Derrida comenta o Ensaio, abordando essas discussóes as quais ocuparam comentadores importantes, como Derathé e Starobinski, para mencionar apenas dois deles. A hipótese que Derathé julga ser mais razoável é a de que o Ensaio, pelo menos no que diz respeito aos capítulos IX e X, seria uma peça destinada ao Segundo Discurso, uma vez que eles apresentam as mesmas preocupaçóes dessa obra. Já Starobinski se manifesta contrariamente, justamente em relação ao conteúdo do capitulo IX, que, segundo ele, apresenta argumentos incompatíveis com a intenção do Segundo Discurso, afirmando que o Ensaio seria sistemática e historicamente anterior àquele e que teria havido uma evoluçáo do pensamento de Rousseau de uma obra para outra. Um dos argumentos de Starobinski a favor da anterioridade do Ensaio concerne ao estatuto da piedade.

Se, no Segundo Discurso, a piedade é um tipo de afeição ou virtude natural que precede o uso da reflexão, no Ensaio, é evidente que a piedade se manteria eternamente inativa, se a imaginação não a despertasse, o que exigiria operaçóes intelectuais ainda inativas no homem primitivo, como explicita o Segundo Discurso. Derrida se empenha em mostrar que não existe, de fato, essa incompatibilidade entre as duas obras, salientando que Rousseau faz de início, no Ensaio, uma concessão que garantiria seu alojamento a toda teoria dita "ulterior" da piedade. Ao escrever "[...] a piedade, ainda que natural ao coração do homem" (DERRIDA, 2008, p. 174), Rousseau estaria reconhecendo na piedade uma virtude inata, espontânea, pré-reflexiva. Além disso, afirma Derrida, é preciso perceber que há uma distinção entre imaginação e razão, e, "[...] de acordo com o Segundo Discurso, a razão e a reflexão comportam 
o risco de sufocar ou alterar a piedade natural. A razão que reflete não é contemporânea da piedade e o Ensaio não diz o contrário, pois a piedade não é despertada pela a razão, é a imaginação que a arranca de sua inatualidade adormecida” (DERRIDA, 2008, p. 222).

Victor Goldschmidt oferece uma interpretação mais precisa. Ele também não concorda que haja contradição nas obras mencionadas quanto ao estatuto da piedade. $\mathrm{O}$ comentador defende, de fato, uma evolução ou "mutação" no interior do próprio Segundo Discurso, pois pensar que Rousseau tenha julgado o homem primitivo capaz de identificação é conceder a ele uma contradição de pensamento bem mais absurda do que a que se acredita constatar entre o Segundo Discurso e as outras obras.

Goldschmidt expóe todas as dificuldades enfrentadas para remontar ao estado de natureza e os recursos e empréstimos feitos por Rousseau, a fim de estabelecer e dar um tom original aos princípios de amor de si e piedade, posicionando-se a favor de uma unidade. A piedade seria a limitação espontânea ao amor de si, formando, assim, um corpo com ele (GOLDSCHMIDT, 1974, p. 354). A identificação se enraíza no amor de si e toma nele o seu impulso, tratando-se de um movimento expansivo, de forma que cita Rousseau, para enfatizar que esse movimento permanece sendo ditado pelo "[...] desejo do meu bem-estar onde quer que eu me sinta existir" (ROUSSEAU, 1964, p. 523). Desse modo, de acordo com Goldschmidt, o que acontece não é a atribuição ao homem isolado da contraditória faculdade de se identificar com o outro, uma vez que a descoberta do alter ego só se daria mais tarde. Mas, unicamente, a pretensão de estabelecer as raízes naturais da piedade em relação ao amor de si, ou seja, o que acontece é um "enraizamento biológico" da piedade. Para reforçar seu argumento, Goldschmidt lembra a distinção que Rousseau faz entre o homem primitivo do primeiro estágio e o homem selvagem. No primeiro, o princípio da piedade representaria apenas o limite imposto ao amor de si, porém, no estágio seguinte, o homem selvagem já teria sofrido uma transformação do seu amor de si e, embora não fosse ainda o amor próprio, poderia entáo ocorrer um tipo de comparação ainda rudimentar e, dessa maneira, o fenômeno da identificação com o outro teria sido possível.

Para retomar a teoria da possível derivação do princípio da piedade do princípio primordial do amor de si, conformando o "puro movimento da natureza”, é de extrema importância o estudo de Pierre Burgelin, em La philosophie de l'existence de Jean-Jacques Rousseau. O autor dedica um capítulo inteiro à temática da expansão, no qual explica o que chama de "[...] um 
tipo de dialética afetiva, ou seja, o primeiro movimento da alma, o de voltarse sobre si, desvelando no sentimento de existência nossa liberdade absoluta, reclama um segundo movimento, o de expansão". E esse é um movimento vital, pois não se trata de uma simples necessidade psicológica, mas de "[...] uma lei universal do espírito, revelando assim a generosidade da sua natureza" (BURGELIN, 1973, p. 151). Nesses termos, não é difícil vislumbrar a possibilidade de confirmação da hipótese que se levantou, no início deste artigo, a de que o amor de si engendra a piedade.

A piedade traduziria o transporte da alma para fora de si mesma, movimento consequente ao aderir-se a si (replier sur soi), próprio do amor de si. No estado de natureza, ela assume a forma de uma virtude natural $^{6}$, uma manifestação absolutamente não-reflexiva, estritamente imanente e propriamente afetiva, a qual se tornará ativa somente a partir de desenvolvimentos ulteriores, com o despertar da imaginação que a porá em atividade. Portanto, é sobre a expansão do amor de si, isto é, sobre o movimento consequente ao voltar-se sobre si, absolutamente natural, que repousam as modalidades específicas da piedade. Seja na condição de "virtude natural”, que, no estado de natureza "[...] nos leva, sem reflexão, a socorrer aqueles que vemos sofrer” (ROUSSEAU, 1964, p. 156), seja na condição de "virtude social", em que o transporte para fora de si permite a identificaçáo com o outro.

Esta é uma interpretação que elucidaria certas passagens do Emílio, as quais indicam o papel que a teoria da expansão desempenha na dimensão moral do homem. Para educar um jovem, Rousseau afirma que é preciso seguir certos caminhos para penetrar em seu coração, a fim de "[...] excitar nele os primeiros movimentos da natureza, desenvolvê-lo e estendê-lo sobre seus semelhantes" (ROUSSEAU, 1969, p. 510). E, por analogia, e a título de corroborar a nossa hipótese, pode-se ainda evocar o que Rousseau estabelecera no Segundo Discurso, ao ressaltar que o movimento natural mais poderoso é o amor de si, que tanto é o móvel da existência física quanto o será da existência moral.

\footnotetext{
${ }^{6}$ Nesse caso, é preciso esclarecer que a palavra virtude não corresponde a nenhum tipo de ação movida por uma "razão prática"; que o ato refletido de piedade de "socorrer aqueles que vemos sofrer" não é próprio do estado de natureza original, mas de um momento posterior, em que as relaçōes sociais já começaram a acontecer.
} 
VENTO, Marisa Alves. The status of pitié in the works of Rousseau. Trans/Form/Ação, Marília, v. 38, p. 139-1162, 2015. Edição Especial.

\begin{abstract}
The hypothesis presented in this article is that pitié, or the "second principle", which Rousseau claims to have found by "contemplating the first and simplest operations of the human soul", is not antagonistic to the first principle (amour de soi). I intend to show how the radical dualism of the principles can yield before the evidence of a unity represented by a double movement: rentrer sur soi and self-expansion (which is the expression of compassion). From this point of view, the "second principle" has a complementary status to love of self, and not an opposing one as some interpretations propose. However, this is a complex discussion involving controversies among the interpreters of Rousseau, a discussion which concerns the possible divergence of the concept of compassion in the Discourse on Inequality, Emile, and the Essay on the Origin of Languages, and also involves questions about the date of the writing of the latter work.
\end{abstract}

KEYWORDS: Rousseau. Love of self. Compassion.

\title{
REFERÊNCIAS
}

BACZKO, Bronislaw. Solitude et communauté. Traduit par Claire Brendhel-Lamhout. Paris: Mouton, 1974.

BURGELIN, Pierre. La philosophie de l'existence de J.-J. Rousseau. Paris: Vrin, 1973.

DERATHÉ, Robert. Le rationalisme de Jean Jacques Rousseau. Paris: PUF, 1948.

DERRIDA, Jacques. Gramatologia. Tradução de Miriam Schnaiderman e Renato Janine Ribeiro. São Paulo: Perspectiva, 2008.

FINE, Peter Martin. Vauvenargues and La Rochefoucauld. Manchester: Manchester University Press, 1974.

GÉLLY, Rafaël. Souffrance et attention socialle à la vie: éléments pour une phenomenology radicale du soin. Bulletin d'Analyse Phénoménologique, v. 5, p. 1-29, 2009.

GOLDSHMIDT, Vitor. Anthropologie et politique: les principes du système de Rousseau. Paris: Vrin, 1974.

HENRY, Michel. Incarnation: une philosophie de la chair. Paris: Seuil, 2000.

MASTERS, Roger D. La philosophie politique de Rousseau. Tradução de Gérard Collonna d'Istria e Jean Pierre Guillot. Lyon: ENS Éditions, 2002.

ROUSSEAU, Jean Jacques. Oeuvres complètes. Paris: Gallimard, 1959-1969. v. 1-4. (Bibliothèque de la Pléiade).

VINCENTI, Luc. Jean-Jacques Rousseau l’individu et la république. Paris: Kimé, 2001.

Recebido / Received: 15/04/2015

Aprovado / Approved: 24/06/2015 